Article

\title{
Estimating Mangrove Canopy Height and Above-Ground Biomass in the Everglades National Park with Airborne LiDAR and TanDEM-X Data
}

\author{
Emanuelle A. Feliciano ${ }^{1,2,3, *}$ (D), Shimon Wdowinski ${ }^{1,4}$, Matthew D. Potts ${ }^{5}$, Seung-Kuk Lee ${ }^{2,6}$ \\ and Temilola E. Fatoyinbo ${ }^{2}$ \\ 1 Department of Marine Geosciences, University of Miami-Rosenstiel School of Marine and Atmospheric \\ Science, 4600 Rickenbacker Causeway, Miami, FL 33149, USA; swdowins@fiu.edu \\ 2 NASA Goddard Space Flight Center, Biospheric Sciences Laboratory, 8800 Greenbelt Road, Greenbelt, \\ MD 20771, USA; seungkuk.lee@nasa.gov (S.-K.L.); lola.fatoyinbo@nasa.gov (T.E.F.) \\ 3 Universities Space Research Association, 7178 Columbia Gateway Dr., Columbia, MD 21046, USA \\ 4 Department of Earth and Environment, Florida International University, 11200 SW 8th Street, AHC5-388, \\ Miami, FL 33199, USA \\ 5 Department of Environmental Science, Policy and Management, University of California, \\ 130 Mulford Hall \#3114 Berkeley, Berkeley, CA 94720, USA; mdpotts@berkeley.edu \\ 6 Department of Geographical Sciences, University of Maryland, 2181 Samuel J. LeFrak Hall, \\ 7251 Preinkert Dr., College Park, MD 20742, USA \\ * Correspondence: emanuelle.a.feliciano@nasa.gov; Tel.: +1-301-614-6639
}

Academic Editor: Lars T. Waser

Received: 1 June 2017; Accepted: 4 July 2017; Published: 7 July 2017

\begin{abstract}
Mangrove forests are important natural ecosystems due to their ability to capture and store large amounts of carbon. Forest structural parameters, such as canopy height and above-ground biomass (AGB), provide a good measure for monitoring temporal changes in carbon content. The protected coastal mangrove forest of the Everglades National Park (ENP) provides an ideal location for studying these processes, as harmful human activities are minimal. We estimated mangrove canopy height and AGB in the ENP using Airborne LiDAR/Laser (ALS) and TanDEM-X (TDX) datasets acquired between 2011 and 2013. Analysis of both datasets revealed that mangrove canopy height can reach up to $\sim 25 \mathrm{~m}$ and AGB can reach up to $\sim 250 \mathrm{Mg} \cdot \mathrm{ha}^{-1}$. In general, mangroves ranging from $9 \mathrm{~m}$ to $12 \mathrm{~m}$ in stature dominate the forest canopy. The comparison of ALS and TDX canopy height observations yielded an $R^{2}=0.85$ and Root Mean Square Error (RMSE) $=1.96 \mathrm{~m}$. Compared to a previous study based on data acquired during 2000-2004, our analysis shows an increase in mangrove stature and AGB, suggesting that ENP mangrove forests are continuing to accumulate biomass. Our results suggest that ENP mangrove forests have managed to recover from natural disturbances, such as Hurricane Wilma.
\end{abstract}

Keywords: mangroves; LiDAR; TanDEM-X; canopy height; above-ground biomass; forest structure

\section{Introduction}

In an era of anthropogenic climate change, mangrove forests are important natural ecosystems due to their ability to capture and store carbon as well as to protect coastal areas from erosion $[1,2]$. In order to evaluate the climate mitigation potential of mangrove forests, it is important to monitor changes in their forest structure and biomass-carbon content. Forest parameters such as the vertical structure (canopy height) and above-ground biomass (AGB) provide useful quantitative measures of carbon stock. Such observations would enable tracking mangrove recovery after destructive extreme weather events and climate change-related phenomena. However, monitoring mangrove forests is 
challenging due to their large spatial extent and limited accessibility. High-resolution remote sensing technologies have the potential to overcome these challenges.

The vertical structure of forest ecosystems has previously been studied using multi-spatial airborne and space-borne remote sensing sensors. The main airborne forest surveying technique has been Airborne LiDAR/Laser Scanning (ALS) [3,4], which is very useful and accurate, but expensive compared to satellite imagery. Space-borne techniques have included Ice, Cloud and Land Elevation Satellite (ICESat) [5], Very-High Resolution (VHR) stereophotogrammetry [6], the Shuttle Radar Topography Mission (SRTM) [3,7], and the TerraSAR-X add-on for Digital Elevation Measurement/TanDEM-X (TDX) [8-10]. The advantages of space-borne observations include their large area coverage and their availability to researchers at no or reduced cost. However, the accuracy and spatial resolution of space-borne observations is reduced compared to ALS.

The use of ALS observations for validating or calibrating satellite data, provides a means for improving space-borne remote sensing forest structure estimates $[8,10]$. Simard et al. (2006) used both airborne and space-borne remote sensing techniques to estimate canopy height and AGB in the Everglades National Park (ENP). Their study, which was conducted a decade ago, used ALS data acquired in 2004 in conjunction with SRTM data acquired in 2000 [3]. The resolution and accuracy of their study, $30 \mathrm{~m}$ horizontal (pixel) resolution and $2 \mathrm{~m}$ in the vertical direction, reflect the accuracy of the SRTM dataset. Over the past decade, new sensors have emerged for obtaining higher resolution topography measurements. One of these sensors is TDX, which was launched in June 2010 with a main mission objective to produce a worldwide high resolution $(<2 \mathrm{~m}$ relative vertical accuracy and $12 \mathrm{~m}$ horizontal raster spacing) Digital Elevation Model (DEM). The TDX mission uses Interferometric Synthetic Aperture Radar (InSAR) observations with its twin satellite TerraSAR-X [11].

In this research, we restudy the same areas as Simard et al. [3] using more advanced and accurate forestry remote sensing techniques and with observations acquired more than a decade after those acquired in [3]. The more accurate remote sensing techniques allow us to make a better assessment of canopy height and AGB of the ENP mangrove forest. In addition, a comparison between our results and Simard's also allow us to detect decadal scale changes in the ENP mangrove forest. During the decade separating the two surveys (Simard: 2000-2004 and ours: 2011-2013) Hurricane Wilma in 2005 caused severe damage to ENP mangrove forests adjacent to the Gulf of Mexico [12]. The comparison between both surveys enables us to evaluate lasting changes in the mangrove structure due to natural disturbances.

\section{Study Area}

Our study area includes the entire mangrove forests located in the ENP (Figure 1), which were previously estimated to cover an area of 144,447 ha [3]. The mangrove forests are composed of multiple species, including Rhizophora mangle (Red mangrove), Laguncularia racemosa (White mangrove) and Avicennia germinans (Black mangrove). For this study, an ALS dataset was acquired to estimate mangrove canopy height along a Shark River Slough (SRS) transect that has been extensively researched by the Florida Coastal Everglades-Long Term Ecological Research Network scientific community. In this transect there are three well-studied sites (SRS-4, SRS-5, SRS-6) with mangrove communities that differ in canopy height: short $(<5 \mathrm{~m})$ (SRS-4), intermediate $(<12 \mathrm{~m})$ (SRS-5) and tall $(12-25 \mathrm{~m})$ (SRS-6) (Figure 1c-f). Mangrove canopy height can reach up to $\sim 25 \mathrm{~m}$ in the western boundary of the park, where SRS connects with the Gulf of Mexico. R. mangle dominates SRS-4 and SRS-5, whereas R. mangle, L. racemosa, and A. germinans are more evenly distributed in SRS-6. SRS resembles the overall spatial distribution of mangrove stature and species in the ENP. 


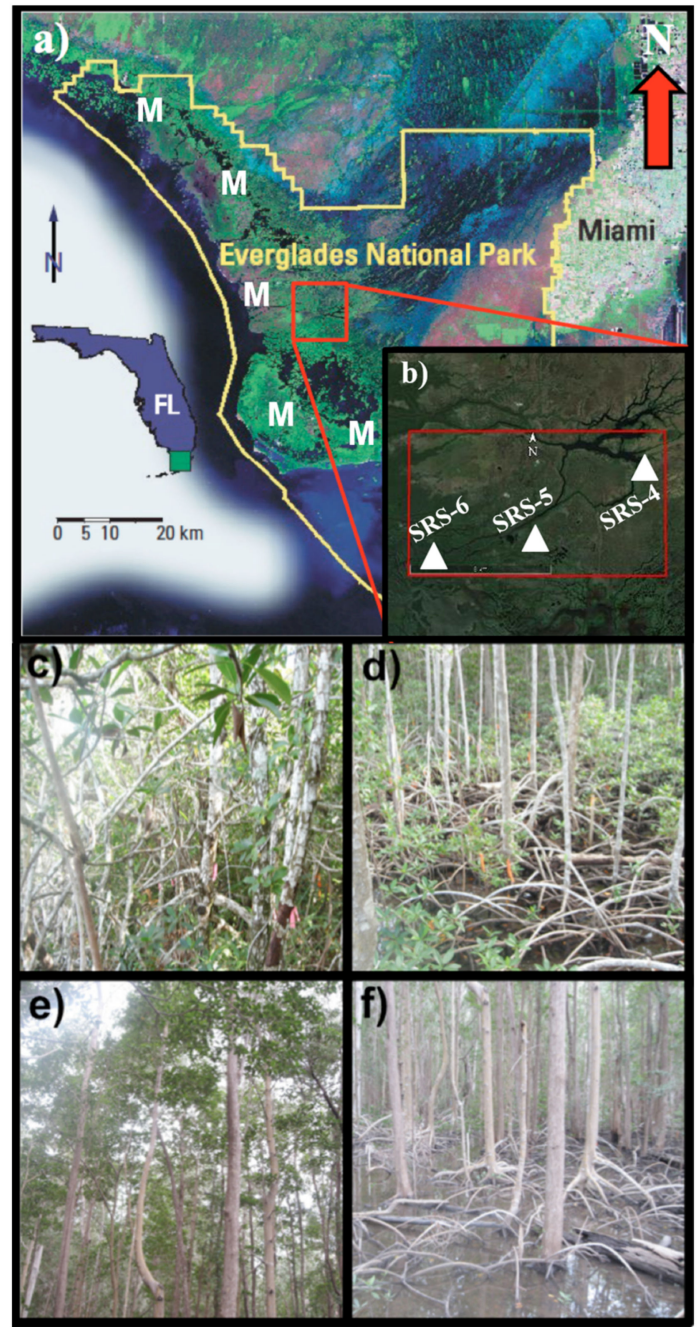

Figure 1. (a) Everglades National Park (ENP) location map within the South Florida Peninsula showing mangrove (M) forests location; (b) Zoom-in to Shark River Slough (SRS) area. The red polygon shows SRS sites; (c) Short mangrove stands (SRS-4); (d) Intermediate mangrove stands (SRS-5); (e) Tall mangrove stands (SRS-6); (f) Tall mangrove stands (SRS-6).

\section{Datasets and Methods}

We acquired and processed three datasets, which are described in the sub-sections ALS, WorldView-2 imagery, and TDX. The ALS dataset was acquired within a limited swath along SRS and was used to estimate and validate mangrove canopy height estimated from TDX data. WorldView-2 imagery was used to create a mangrove cover map inside the boundaries of the ENP. The SRTM Water Body Data (SWBD) was used in the WorldView-2 imagery-based mangrove mask. The TDX data were used to estimate canopy height for the entire ENP mangrove forest.

\subsection{Airborne Measurements}

We acquired ALS data along a $30 \mathrm{~km}^{2}$ transect that covers the mangrove stature gradient across SRS (Figure 1b). The data were acquired on 17 November 2012 using an Optech Airborne Laser Terrain Mapper (ALTM) operated by the National Center for Airborne Laser Mapping (NCALM). Technical specifications for this survey are provided in Table 1. The first laser returns, which mark the location of tree canopies, were interpolated and gridded to generate a 1-m resolution Digital Surface Model (DSM) (Figure 2a). The last laser returns, which mark the location of the ground surface, were interpolated 
and gridded to generate a 1-m resolution Digital Terrain Model (DTM) (Figure 2b). We produced a 1-m resolution digital canopy model (DCM) (Figure 2c) by subtracting the DTM created with the bare ground points from the DSM created with the top of the canopy points. The DCM was georeferenced into the North American Datum of 1983 (NAD83) and Universal Transverse Mercator (UTM) zone 17 $\mathrm{N}$ projection.

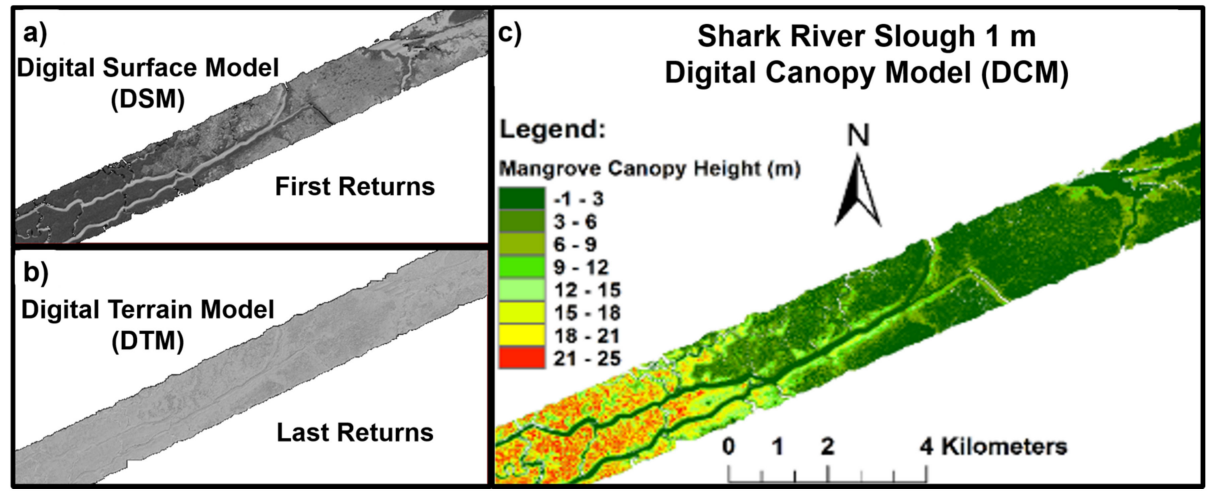

Figure 2. Airborne LiDAR/Laser (ALS)-derived elevation products for the SRS swath. (a) Digital Surface Model (DSM) hillshade; (b) Digital Terrain Model (DTM) hillshade; (c) A digital canopy model (DCM) created by subtracting the DTM from the DSM.

Table 1. Optech Gemini Airborne Laser Terrain Mapper (ALTM) specifications for Everglades National Park survey.

\begin{tabular}{cc}
\hline \multicolumn{2}{c}{ Optech Gemini ALTM Specifications } \\
\hline Flight Altitude & $600 \mathrm{~m}$ \\
Flight Speed & $60 \mathrm{~m} / \mathrm{s}$ \\
Swath Width & $360 \mathrm{~m}$ \\
Swath Overlap & $50 \%$ \\
Point Density & $6.4 \mathrm{p} / \mathrm{m}^{2}$ \\
Laser Pulse Rate Frequency & $125 \mathrm{kHz}$ \\
Beam Divergence & $0.25 \mathrm{mrad}$ \\
Scan Frequency & $45 \mathrm{~Hz}$ \\
Scan Angle & $\pm 21^{\circ}$ \\
\hline
\end{tabular}

ALS-derived canopy heights were converted into H100 canopy height, which is extensively used in forestry studies and is defined as the mean canopy height of the 100 tallest trees on a hectare $[9,13]$. ALS H100 has been used to compare the vertical structure of mangrove forests using satellite datasets from optical and radar sensors [6,8]. The ALS H100 DCM was resampled to $12 \mathrm{~m}$ to compare its results with the TDX canopy height results.

\subsection{Space-Based Measurements}

\subsubsection{WorldView-2 Mangrove Cover Map}

We used seven WorldView-2 optical images, which were acquired between November 2010 and December 2012 (Figure 3a), to create a mangrove cover map of the ENP (Figure 3b), as the most recent vegetation map was created in 1999. The purpose of the mangrove cover map is to constrain the study area to the mangrove region inside the park and mask this region from the TDX data as the focus of this study is the mangrove forest. The high-resolution (1.84 m Multispectral, $0.46 \mathrm{~m}$ Panchromatic) images were atmospherically corrected, mosaicked (Figure 3a) and classified using a supervised classification. Mangroves have a distinct bright reddish spectral signature that is very noticeable in the infrared spectrum (False Color Composite: Bands 7-5-3). The Fast Line-of-sight 
Atmospheric Analysis of Spectral Hypercubes (FLAASH) atmospheric correction module was applied using ENVI software in order to correct atmospheric effects and get accurate estimates of surface reflectance. The classification step consisted of a supervised classification in ENVI/IDL software that used training points of mangrove versus non-mangrove regions.
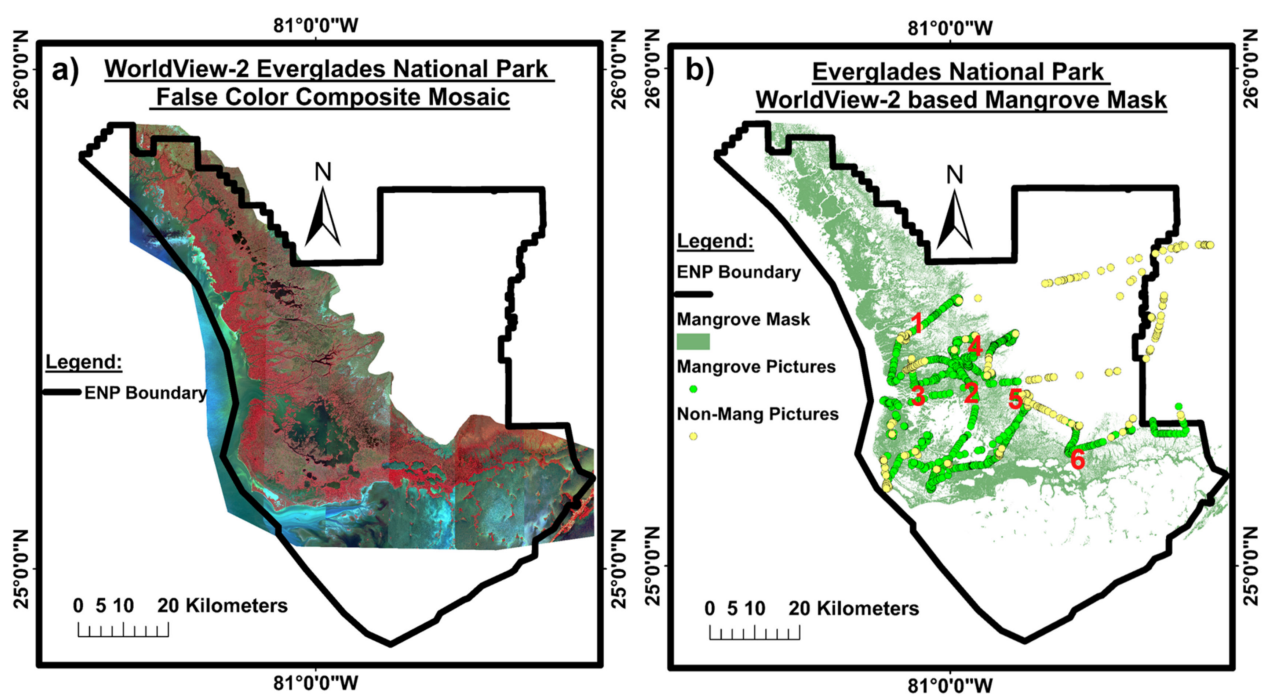

Figure 3. (a) WorldView-2 imagery (7 scenes) used to classify mangrove cover. Mangrove cover shows a bright red spectral signature, mostly located at the Western and Southwestern areas of the map; (b) Mangrove cover mask created with WorldView-2 and validation points obtained from high-resolution geo-tagged airborne photography. Red numbers show the locations of photos shown in Figure 4.

The supervised classification was used to isolate and cluster pixels of similar spectral signature into two classes (mangroves and non-mangroves). To validate and train the mangrove versus non-mangrove classification, high-resolution geotagged helicopter photography ( 2000 photos) was acquired in June 2014 (Figure 4). A total of 200 (100 mangrove; 100 non-mangrove) points (photos) were used to train the supervised classification, and 200 (100 mangrove; 100 non-mangrove) points were used to validate the classification. Our classification results indicate that mangrove forest extends over an area of 131,813 ha in the ENP.

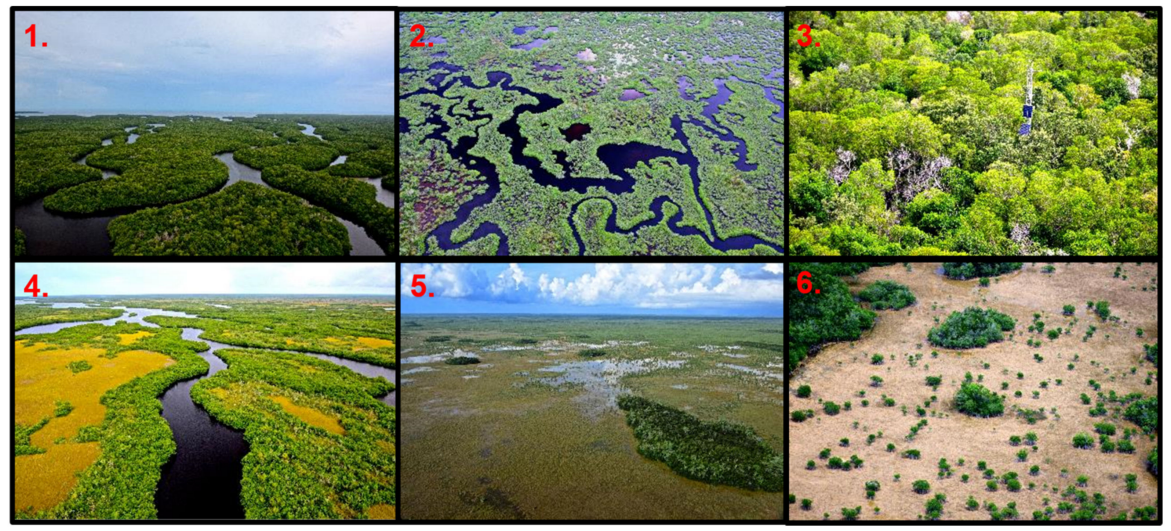

Figure 4. Example of geotagged photography acquired inside the Everglades National Park boundaries. (1.) Mangroves at the mouth of SRS; (2.) Short mangroves; (3.) Tall mangroves in SRS-6 site; (4.) Short mangroves and sawgrass located at the Northwestern region of SRS; (5.) Tree islands and mangroves near the boundary of the mangrove transition zone; (6.) Mixture of tree islands and short mangroves. 


\subsubsection{TanDEM-X Data}

Four TDX scenes were acquired, processed and mosaicked to cover the entire ENP mangrove forests (Table 2). The scenes were single-polarized (HH) and were acquired in bistatic stripmap mode, in which one satellite emits the signal and both satellites receive the backscattered signal nearly at the same time with negligible temporal decorrelation [11]. The single-polarized scenes were retrieved from the German Aerospace Center (DLR) global DEM acquisition archive. The processing of TDX data to obtain mangrove forest height was based on Pol-InSAR inversion, which is used to constrain a volume scattering model known as Random Volume over Ground Model (RVoG) $[8,14,15]$ (Figure 5). Pol-InSAR permits the investigation of scattering mechanisms in natural volume scatterers, such as forests, by assuming that interferometric coherence is related to the vertical distribution of scatterers. A recent study by Lee and Fatoyinbo [8], successfully used dual-pol and single-pol TDX data to extract mangrove forest height information using the RVoG model. Usually, the inversion of single-polarization data for forest height includes the information of an external DTM. However, DTMs are not available for most mangrove forests due to high vegetation density or absence of LiDAR data. Lee and Fatoyinbo [8] suggested a way to estimate the ground topography and phase directly from the TDX interferogram, assuming flat topography as mangroves are located at or near sea level. This assumption proved successful in generating a DCM of the mangrove forests of Zambezi Delta, Mozambique [8]. Our study follows the same procedures outlined and suggested by Lee and Fatoyinbo [8] to invert single-polarization raw TDX data into mangrove forest canopy height in the ENP (Figure 6).

Table 2. TanDEM-X (TDX) scenes acquired and processed in this study.

\begin{tabular}{ccccccc}
\hline Acquisition Date & $\begin{array}{c}\text { UTC Time } \\
\text { (hh:mm:ss) }\end{array}$ & Polarization & $\begin{array}{c}\text { Incidence } \\
\text { Angle } \mathbf{(}^{\circ}\end{array}$ & $\begin{array}{c}\text { Height of } \\
\text { Ambiguity }\end{array}$ & $\begin{array}{c}\text { Bandwidth } \\
\text { (MHz) }\end{array}$ & $\begin{array}{c}\text { Effective } \\
\text { Baseline (m) }\end{array}$ \\
\hline 6 March 2011 & $23: 30: 39$ & HH & 46.27 & 39.54 & 100 & 203 \\
9 November 2011 & $23: 22: 03$ & HH & 33.85 & -48.73 & 100 & 109 \\
17 May 2013 & $23: 30: 45$ & HH & 48.08 & -60.86 & 100 & 140 \\
17 May 2013 & $23: 30: 52$ & HH & 48.08 & -60.68 & 100 & 141 \\
\hline
\end{tabular}
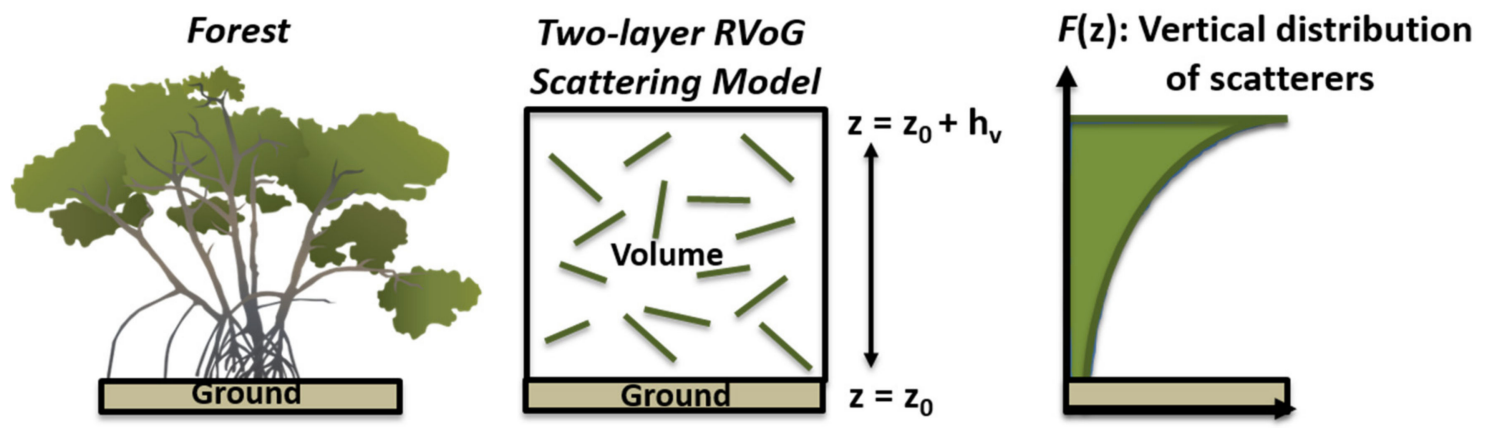

Figure 5. Schematic illustration of the Random Volume over Ground (RVoG) model modified after Treuhaft et al. [14]. 


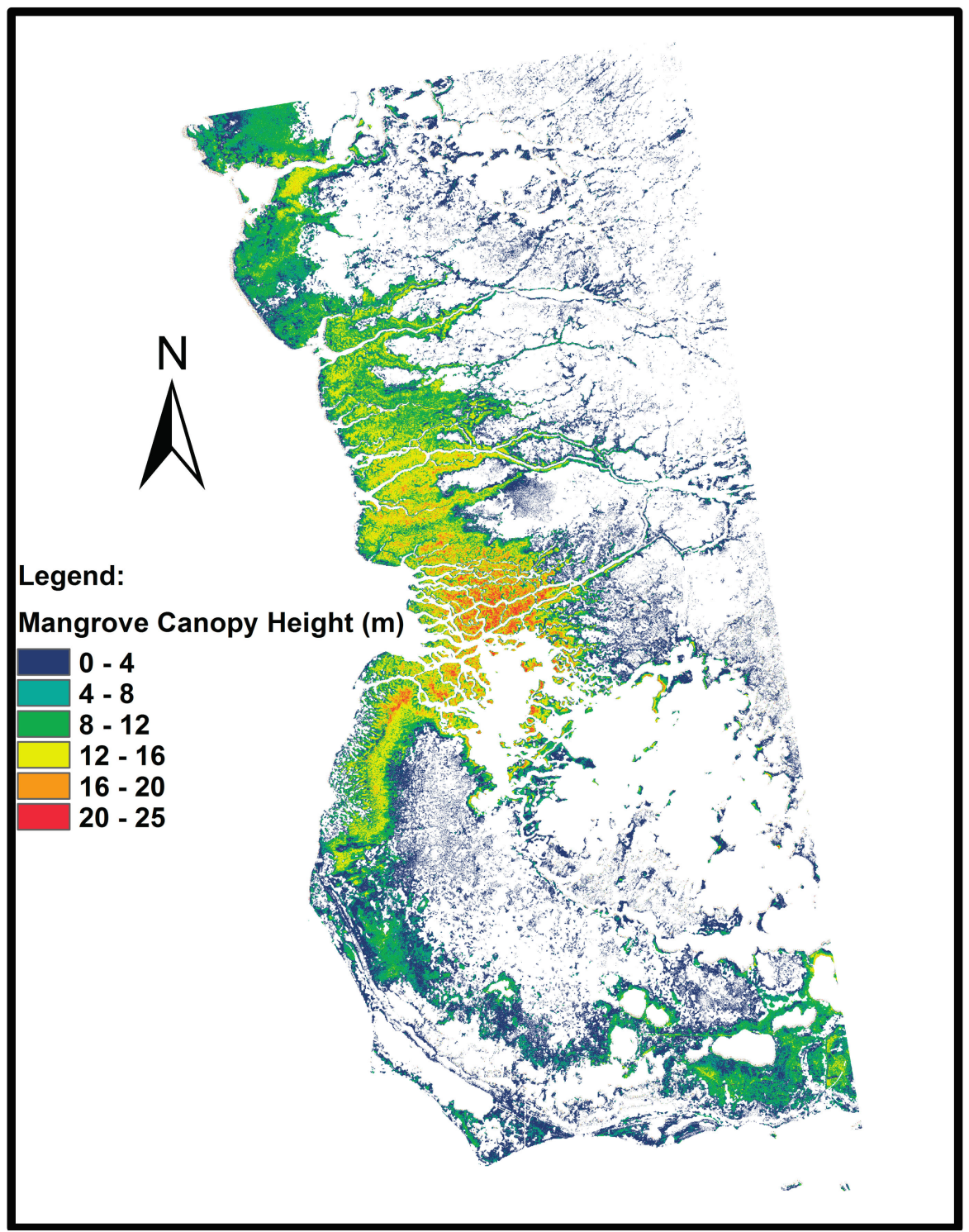

Figure 6. Example of canopy height DCM after TDX Pol-InSAR inversion. This image encompasses one TDX scene on the Western region of the Everglades National Park.

\section{Results}

\subsection{Quality Assessment of the TanDEM-X Results}

The Pol-InSAR inversion results provide a detailed DCM of the mangrove forest in the ENP with resolution of $12 \mathrm{~m}$ (Figure 6). In order to assess the quality of the TDX results, we compared these results with the ALS H100-derived DCM calculated from the ALS data acquired along the SRS. A linear regression analysis indicated a very good agreement between the ALS H100-based DCM and the SRS TDX-based DCM results (Figure 7). The validation plot between the ALS and TDX mangrove canopy heights in SRS yielded an $R^{2}$ correlation coefficient of 0.85 and an RMSE of $1.96 \mathrm{~m}$ (Figure 7c). 


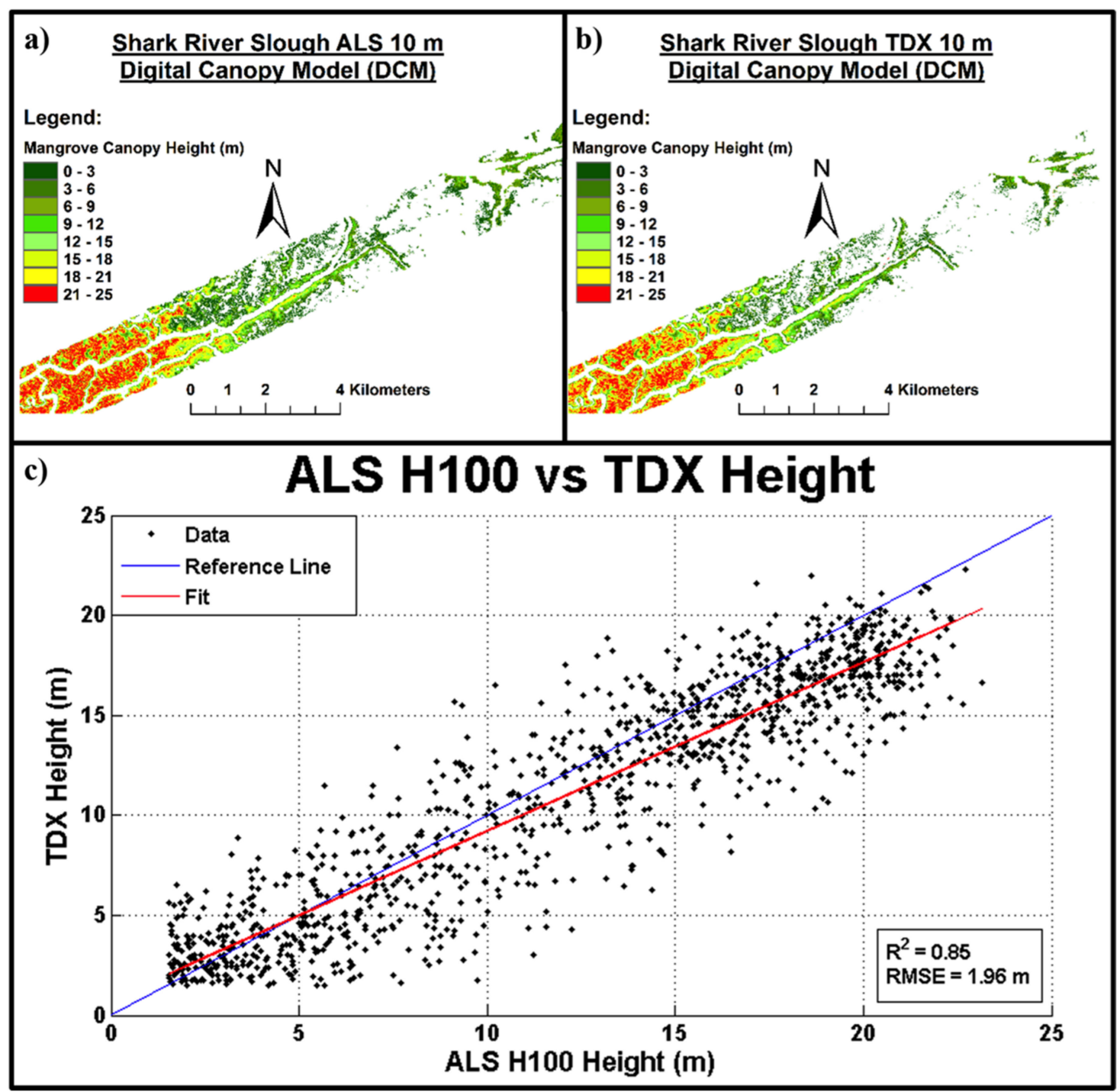

Figure 7. A comparison between ALS H100 and TDX canopy height results along the SRS swath. (a) ALS H100-derived 12-m SRS DCM; (b) TDX-derived 12-m SRS DCM; (c) Linear regression between ALS H100 and TDX mangrove canopy height in SRS yielding an $R^{2}=0.85$ and RMSE $=1.96 \mathrm{~m}$.

\subsection{Everglades National Park Mangrove Digital Canopy Model}

The large extent of mangrove forest in the ENP required the use of multiple TDX scenes. The four processed TDX scenes were mosaicked and georeferenced into a NAD83 datum and the local UTM $(17 \mathrm{~N})$ projection (Table 2, Figure 8$)$. The entire mangrove DCM (12-m horizontal resolution) derived from TDX data is shown in Figure 8, including a zoomed area in the SRS region. We assumed that the same RMSE and $R^{2}$ we obtained for the ALS SRS swath could be applied to all the TDX scenes, as no ALS data are available beyond the SRS swath. The DCM shows that the tallest mangroves forests $(\sim 25 \mathrm{~m})$ are located along the Western coast of the ENP, where SRS connects with the Gulf of Mexico. 


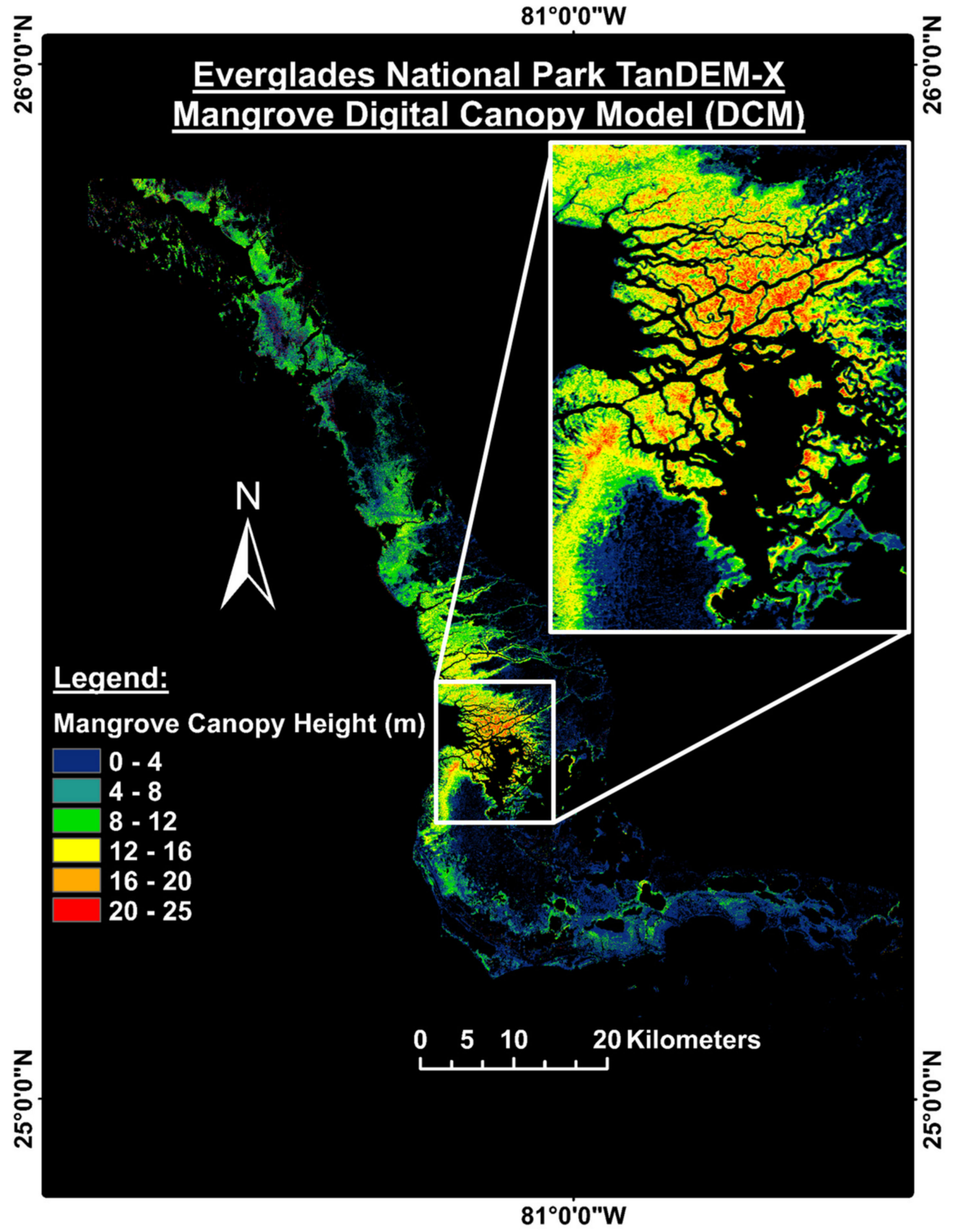

Figure 8. Everglades National Park 12-m resolution TDX-based mangrove DCM with a zoomed area in the SRS region.

\subsection{Above-Ground Biomass Estimation}

We used ALS and TDX canopy heights as input datasets to estimate AGB in the mangrove forests of the ENP. The AGB estimates were based on the following height-to-AGB ENP mangrove allometric equation [3]:

$$
B\left(\mathrm{Mg} \cdot \mathrm{ha}^{-1}\right)=10.0 \times H(\mathrm{~m})
$$

where $B$ is AGB in $\mathrm{Mg} \cdot \mathrm{ha}^{-1}$ and $H$ is canopy height in meters. The allometric equation has an $R^{2}$ of 0.82 and an RMSE of $37 \%$ [3]. The equation was created by a linear regression analysis of AGB estimated from ENP field height and diameter-at-breast-height (DBH) data and non-site specific mangrove allometry in conjunction with SRTM data calibrated with airborne LiDAR height data. In this study, we produced an ALS-based AGB map that covers the mangrove forests along SRS (Figure 9), and a TDX-based AGB map that covers the entire ENP mangrove forests (Figure 10). Both maps indicate that a maximum AGB value of $\sim 250 \mathrm{Mg} \cdot \mathrm{ha}^{-1}$ can be found in the region where SRS connects with the Gulf of Mexico. 


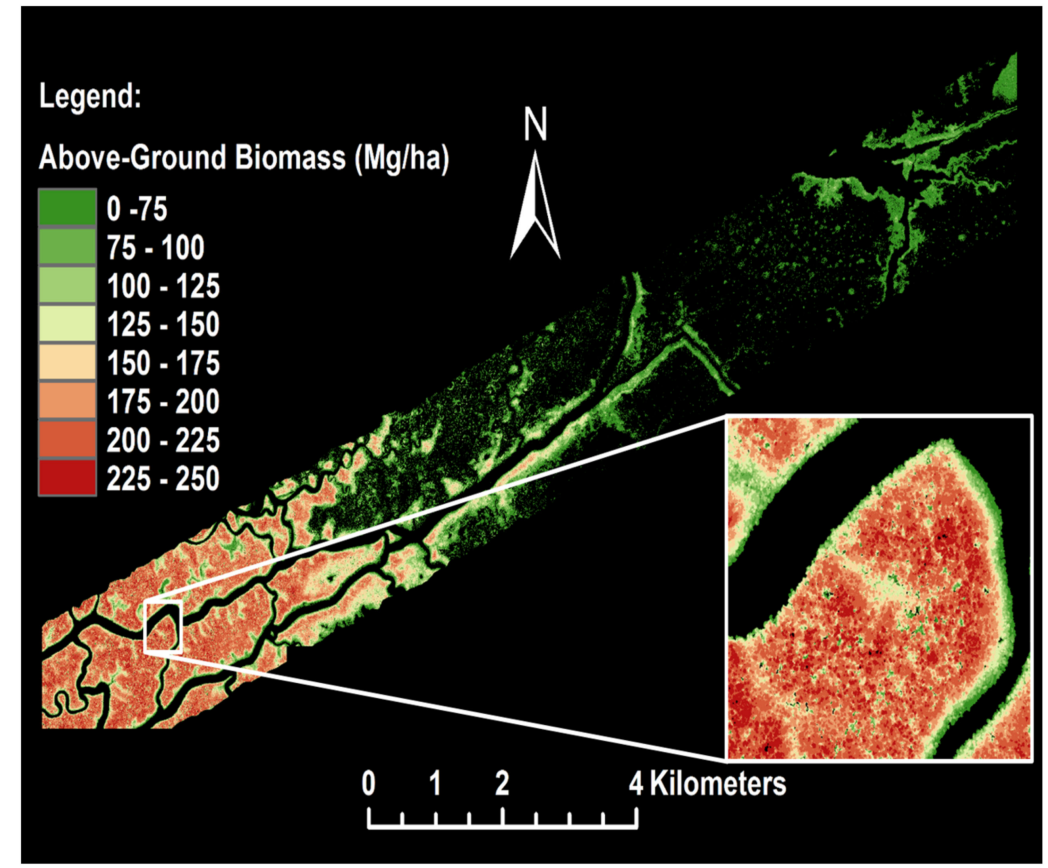

Figure 9. SRS mangrove above-ground biomass (AGB) map based on 2012 ALS canopy height data and Simard et al. [3] ENP mangrove height to AGB equation.

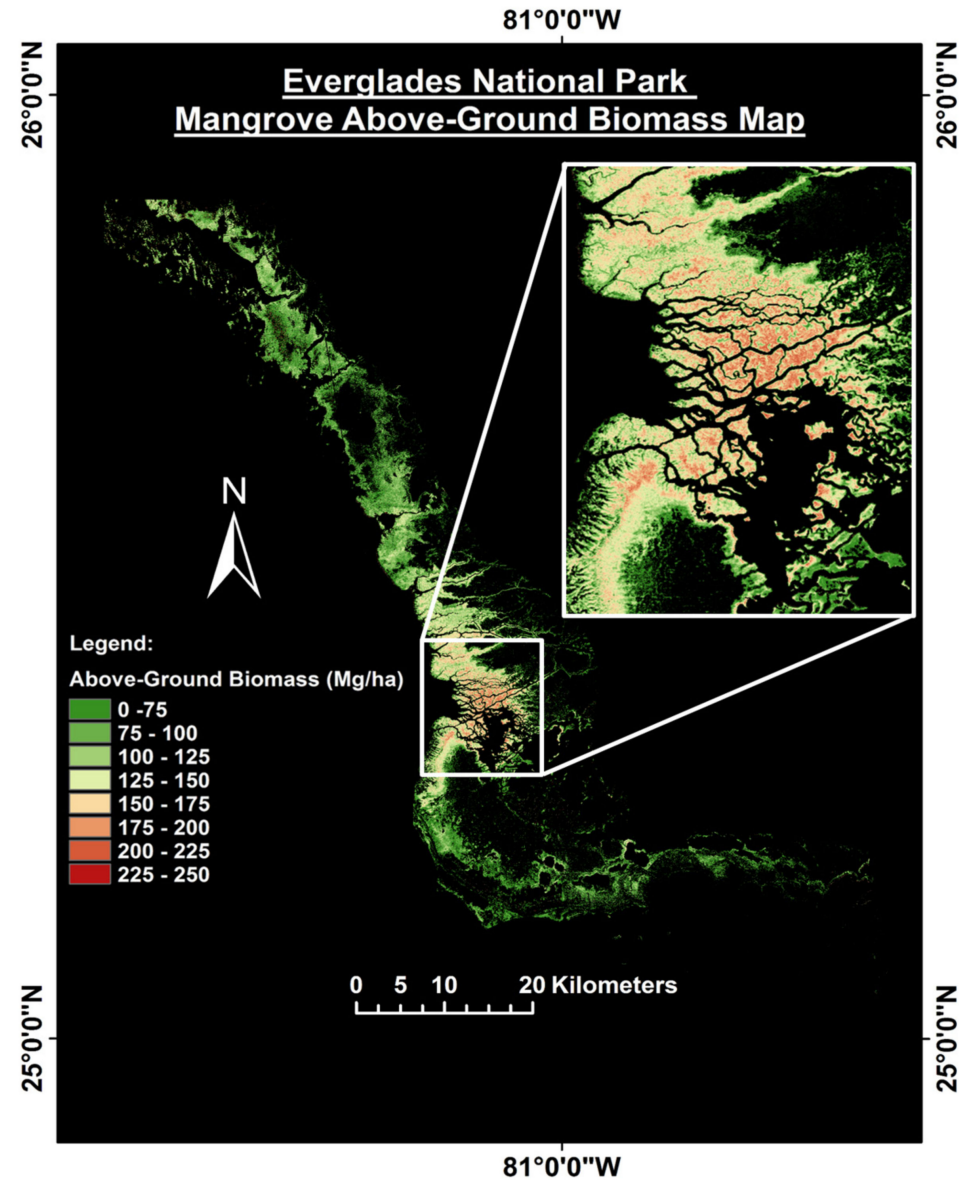

Figure 10. Everglades National Park mangrove AGB map based on TDX canopy height data and Simard et al. [3] ENP mangrove height to AGB equation. 


\section{Discussion}

\subsection{Extent of the ENP Mangrove Forest}

Simard et al. [3] estimated a larger mangrove coverage of 144,447 ha, compared with our estimate of 131,813 ha. The two estimates differ from one another by $8.7 \%$, which is a significant change of mangrove area within a decade. However, this change may reflect the use of different methodologies used in each study, or the fact that our Worldview-2 dataset did not include a Northwest mangrove forest region, which accounts for approximately 5\% (7222 ha) of the total mangrove area according to Simard et al. [3]. Adding 7222 ha to our mangrove area estimate yields a revised total mangrove area of 139,035 ha. The new difference in area is 3.7\% when compared to Simard et al. [3]. Our mangrove cover is based on a supervised classification on WorldView-2 satellite imagery, whereas the Simard et al. [3] mangrove cover was based on the University of Georgia's Center for Geospatial Research 1999 vegetation map, mostly based on aerial photography [16]. The spatial resolution of satellite and airborne sensors will also affect vegetation area estimates. Ongoing efforts to update the ENP vegetation maps will provide within the next few years a better assessment of the vegetation within the park, including that of mangrove forest coverage.

\subsection{Mangrove Canopy Height}

At first glance, our TDX-based mangrove DCM (12-m horizontal resolution) (Figure 11b) yields similar results when visually compared with the SRTM-based mangrove DCM (30 m horizontal resolution) from Simard et al. [3] (Figure 11a). The tallest mangrove forests ( $>16 \mathrm{~m}$ ) on both DCMs (Figure 11) are located along the Western ENP coast, where the Gulf of Mexico connects with SRS. Intermediate-size (12-16 m) mangroves are located north and south of SRS, and in the mid-region of SRS where the SRS- 5 site is located. The rest of the mangrove forests are dominated by small-to-intermediate stature mangroves ranging from 3-12 m. Differences between both DCMs are more noticeable in the SRS-6 site region, where our study shows dominance of mangroves taller than $18 \mathrm{~m}$ and Simard et al. [3] shows the domination of mangroves ranging from $16-18 \mathrm{~m}$ in stature. This difference could potentially represent mangrove growth in this area as approximately one decade has passed between both studies. Overall, our study suggest that mangrove canopy height in the ENP is dominated by mangroves ranging from of $9 \mathrm{~m}$ to $12 \mathrm{~m}$ in stature, whereas Simard et al. [3] found that canopy height was dominated by $8-\mathrm{m}$ tall mangrove stands. Additionally, our results show more regions with concentrations of 25-m tall mangroves. Overall, our study shows that there has been an increase in mangrove canopy height as observed differences are higher than the measurement error of both datasets $(\sim 2 \mathrm{~m})$, hence statistically significant. Furthermore, we are able to detect finer details as our TDX dataset has higher resolution, when compared with SRTM-based results. Future work in the ENP will include the comparison of multi-temporal airborne LiDAR data and optical satellite imagery to more accurately quantify mangrove migration, growth and/or degradation due to naturogenic causes such as sea level rise, droughts and/or hurricanes. For multi-temporal studies the use of similar sensors is vital, as analyzing data from different sensors (e.g., SRTM and TDX) will result in high uncertainty due to differences in spatial resolution and sensor sensitivity [6].

Our TDX-based DCM (Figure 11b) shows fewer short-stature mangrove areas when compared to the SRTM-based DCM (Figure 11a). These areas are composed of mostly short-stature mangroves that our TDX dataset was not able to resolve due to the small spatial baseline at the time of data acquisition [8,17]. TDX data acquisitions with large spatial baselines could potentially solve the issue of not quantifying the canopy height of short stature vegetation $[17,18]$. Remote sensing data products inherently include uncertainty in their estimations. ALS canopy height measurements have an RMSE or accuracy that is less than $1 \mathrm{~m}[4,19]$. The high degree of concordance between our ALS and TDX height estimates $\left(R^{2}=0.85\right.$, RMSE $\left.=1.96 \mathrm{~m}\right)$ indicate a high potential to use TDX data for the estimation of mangrove forest canopy height. The ALS data covered a relatively small area $\left(30 \mathrm{~km}^{2}\right)$ along SRS in only one TDX scene. The additional three TDX scenes were located in areas where ALS data are not 
available, hence, validation was not possible. Overlap regions between TDX scenes were analyzed to find variations in canopy height values. Differences in overlap regions were less than the RMSE, thus we assume the same uncertainty can be applied to all the TDX scenes.
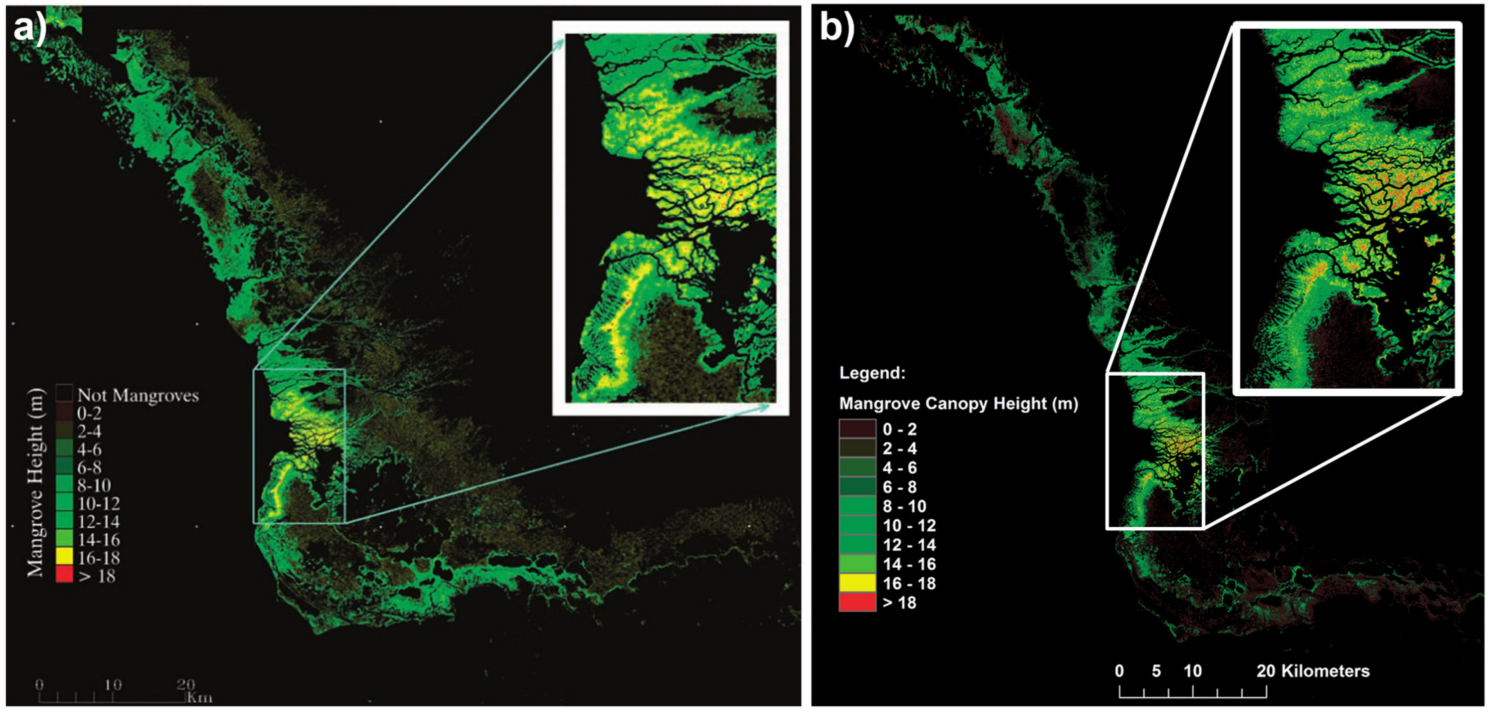

Figure 11. (a) Mangrove DCM published by Simard et al. [3] using Shuttle Radar Topography Mission (SRTM) data; (b) Mangrove DCM produced in this study using TDX data.

\subsection{Mangrove Above-Ground Biomass}

Mangrove AGB was estimated using ENP-specific height-to-biomass allometry (Equation (1)) developed by Simard et al. [3], which applied this equation to SRTM-calibrated data with an absolute vertical uncertainty of $2 \mathrm{~m}$. We applied this equation to our TDX dataset with an absolute vertical uncertainty of $1.96 \mathrm{~m}(\sim 2 \mathrm{~m})$. The standard error for the AGB estimates of the allometric equation (Equation (1)) ranges from $\pm 20 \mathrm{Mg} \cdot \mathrm{ha}^{-1}$ for mangrove stands of $1 \mathrm{~m}$ in stature up to $\pm 40 \mathrm{Mg} \cdot \mathrm{ha}^{-1}$ for mangrove stands of $25 \mathrm{~m}$ in stature [3]. Since the equation is a linear relationship between canopy height and AGB, and both height datasets uncertainties are similar ( 2 $\mathrm{m})$, the detected height differences between the two studies directly translate into AGB differences. Our results show that mangrove AGB in the ENP can reach up to $250 \mathrm{Mg} \cdot \mathrm{ha}^{-1}, 25 \%$ higher than the Simard et al. [3] maximum AGB value of $\sim 200 \mathrm{Mg} \cdot \mathrm{ha}^{-1}$. As with the mangrove canopy height, this difference in AGB estimations could be due to mangrove growth as almost a decade has passed between studies. Our results suggest that most of the mangrove AGB lies between $90 \mathrm{Mg} \cdot \mathrm{ha}^{-1}$ and $120 \mathrm{Mg} \cdot \mathrm{ha}^{-1}$ (9 m-12 m canopy height), whereas most of the AGB in [3] study was located around $80 \mathrm{Mg} \cdot \mathrm{ha}^{-1}(8 \mathrm{~m}$ canopy height). As the height-to-AGB in ENP allometric equation is based on linear regression, canopy height and AGB differences between our study and Simard's study are linear and constant in nature. Our total estimate for mangrove AGB in the ENP mangroves using the Simard et al. [3] equation is $6.7 \times 10^{9} \mathrm{~kg}$. The previous estimate of AGB was $5.6 \times 10^{9} \mathrm{~kg}$ [3]. Our TDX results do not include some short mangrove stands, suggesting a slight underestimation of total AGB.

Our study suggests that there has been an increase in AGB and carbon sequestration during the period of 2000-2013 in the ENP mangrove forests. These results show that the ENP mangrove forests are steadily growing, despite large weather events such as Hurricane Wilma in 2005 [12]. In addition, we were able to obtain more detailed estimates of AGB as our TDX dataset has a very high resolution, compared with SRTM-based AGB estimates. Caution should be taken when converting height to AGB data, as there might be cases where degraded or dead mangrove stands preserve their stem structure and might be interpreted as live AGB in the final estimation. Furthermore, as the ENP height-to-AGB equation [3] was based on non-site-specific AGB allometry [20,21], future studies in 
the Everglades ecosystem should focus on using ENP-specific allometry [22] in order to increase AGB estimation accuracy.

\section{Conclusions}

We used ALS and TDX data to estimate canopy height and AGB in the ENP mangrove forests. TDX mangrove canopy height results were validated with an ALS dataset acquired along SRS. The comparison between the ALS and TDX canopy height results yielded an $R^{2}=0.85$ and RMSE $=1.96 \mathrm{~m}$. Comparing our results to the previous ENP mangrove canopy height map [3], we detected significant changes in canopy height (up to $6 \mathrm{~m}$ ), mainly in the region where SRS connects with the Gulf of Mexico. Our study shows the potential of using TDX data for estimating mangrove canopy height. Global TDX DEM acquisitions are based on single-polarized (HH) data, and this study successfully demonstrates the use of single-polarization data for mangrove research.

AGB was estimated using a published ENP height-to-biomass allometric equation. Our results showed that AGB reaches up to $\sim 250 \mathrm{Mg} \cdot \mathrm{ha}^{-1}$ near the western coastal mangrove forests and that most of the mangrove AGB distribution is concentrated between $90 \mathrm{Mg} \cdot \mathrm{ha}^{-1}$ to $120 \mathrm{Mg} \cdot \mathrm{ha}^{-1}$. We estimate total mangrove AGB in the ENP at $6.7 \times 10^{9} \mathrm{~kg}$, a significant increase compared to the previous AGB estimate of $5.6 \times 10^{9} \mathrm{~kg}$. Our canopy height and AGB results suggest that when analyzed altogether, the ENP mangrove forests have been steadily growing despite disturbances that could have destructive effects. Upcoming work will focus on the analysis of multi-temporal airborne LiDAR data in the extensively studied ENP SRS region to quantify mangrove migration, growth and/or degradation.

Acknowledgments: The research was supported by the National Science Foundation Graduate Research Fellowship Program (NSF-GRFP) under Grant No. DG1E-0951782, the National Science Foundation's Grant No. DEB-1237517 (Florida Coastal Everglades-Long Term Ecological Research - FCE-LTER), and the National Aeronautics and Space Administration (NASA) Cooperative Agreement No. NNX10AQ13A (WaterSCAPES: Science of Coupled Aquatic Processes in Ecosystems from Space). TanDEM-X data were provided by the German Aerospace Center (DLR) and WorldView-2 images were provided by the DigitalGlobe Foundation.

Author Contributions: Feliciano was the lead author of the manuscript, processed the airborne LiDAR and TDX data, in addition of facilitating the collaboration between all authors. Wdowinski and Potts helped with guidance, writing and analysis of the results of the manuscript. Lee and Fatoyinbo helped with the processing and analysis of the TDX dataset and with edits to the manuscript.

Conflicts of Interest: The authors declare no conflict of interest. The funding sponsors had no role in the design of the study; in the collection, analyses, or interpretation of data; in the writing of the manuscript, and in the decision to publish the results.

\section{References}

1. Donato, D.C.; Kauffman, J.B.; Murdiyarso, D.; Kurnianto, S.; Stidham, M.; Kanninen, M. Mangroves among the most carbon-rich forests in the tropics. Nat. Geosci. 2011, 4, 293-297. [CrossRef]

2. Lovelock, C.E.; McAllister, R.R. 'Blue carbon' projects for the collective good. Carbon Manag. 2013, 4, 477-479. [CrossRef]

3. Simard, M.; Zhang, K.; Rivera-Monroy, V.H.; Ross, M.S.; Ruiz, P.L.; Castañeda-Moya, E.; Twilley, R.R.; Rodriguez, E. Mapping height and biomass of mangrove forests in Everglades National Park with SRTM elevation data. Photogramm. Eng. Remote Sens. 2006, 72, 299-311. [CrossRef]

4. Hyyppä, J.; Hyyppä, H.; Litkey, P.; Yu, X.; Haggrén, H.; Rönnholm, P.; Pyysalo, U.; Pitkänen, J.; Maltamo, M. Algorithms and methods of airborne laser scanning for forest measurements. Int. Arch. Photogramm. Remote Sens. Spat. Inf. Sci. 2004, 36, 82-89.

5. Simard, M.; Pinto, N.; Fisher, J.B.; Baccini, A. Mapping forest canopy height globally with spaceborne lidar. J. Geophys. Res. Biogeosci. 2011, 116. [CrossRef]

6. Lagomasino, D.; Fatoyinbo, T.; Lee, S.; Feliciano, E.; Trettin, C.; Simard, M. A Comparison of Mangrove Canopy Height Using Multiple Independent Measurements from Land, Air, and Space. Remote Sens. 2016, 8, 327. [CrossRef] 
7. Fatoyinbo, T.E.; Simard, M.; Washington-Allen, R.A.; Shugart, H.H. Landscape-scale extent, height, biomass, and carbon estimation of Mozambique's mangrove forests with Landsat ETM+ and Shuttle Radar Topography Mission elevation data. J. Geophys. Res. Biogeosci. 2008, 113. [CrossRef]

8. Lee, S.-K.; Fatoyinbo, T.E. TanDEM-X Pol-InSAR Inversion for Mangrove Canopy Height Estimation. IEEE J. Sel. Top. Appl. Earth Obs. Remote Sens. 2015, 8, 3608-3618. [CrossRef]

9. Hajnsek, I.; Kugler, F.; Lee, S.-K.; Papathanassiou, K.P. Tropical-forest-parameter estimation by means of Pol-InSAR: The INDREX-II campaign. IEEE Trans. Geosci. Remote Sens. 2009, 47, 481-493. [CrossRef]

10. Sadeghi, Y.; St-Onge, B.; Leblon, B.; Simard, M.; Papathanassiou, K. Mapping Forest Canopy Height Using TanDEM-X DSM and Airborne LiDAR DTM. In Proceedings of the 2014 IEEE International Geoscience and Remote Sensing Symposium (IGARSS), Quebec City, QC, Canada, 13-18 July 2014.

11. Krieger, G.; Moreira, A.; Fiedler, H.; Hajnsek, I.; Werner, M.; Younis, M.; Zink, M. TanDEM-X: A satellite formation for high-resolution SAR interferometry. IEEE Trans. Geosci. Remote Sens. 2007, 45, 3317-3341. [CrossRef]

12. Smith, T.J.; Anderson, G.H.; Balentine, K.; Tiling, G.; Ward, G.A.; Whelan, K.R. Cumulative impacts of hurricanes on Florida mangrove ecosystems: Sediment deposition, storm surges and vegetation. Wetlands 2009, 29, 24-34. [CrossRef]

13. Aulinger, T.; Mette, T.; Papathanassion, K.; Hajnsek, I.; Heurich, M.; Krzystek, P. Validation of Heights from Interferometric SAR and LIDAR over the Temperate Forest Site "Nationalpark Bayerischer Wald". In Proceedings of the 2nd International Workshop POLINSAR 2005, Frascati, Italy, 17-21 January 2005.

14. Treuhaft, R.N.; Madsen, S.N.; Moghaddam, M.; Zyl, J.J. Vegetation characteristics and underlying topography from interferometric radar. Radio Sci. 1996, 31, 1449-1485. [CrossRef]

15. Cloude, S.; Papathanassiou, K. Three-stage inversion process for polarimetric SAR interferometry. IEEE Proc. Radar Sonar Navig. 2003, 150, 125-134. [CrossRef]

16. Welch, R.; Madden, M.; Doren, R.F. Mapping the Everglades. Photogramm. Eng. Remote Sens. 1999, 65, 163-170.

17. Kugler, F.; Schulze, D.; Hajnsek, I.; Pretzsch, H.; Papathanassiou, K.P. TanDEM-X Pol-InSAR performance for forest height estimation. IEEE Trans. Geosci. Remote Sens. 2014, 52, 6404-6422. [CrossRef]

18. Lee, S.-K.; Kugler, F.; Papathanassiou, K.P.; Hajnsek, I. Quantification of temporal decorrelation effects at L-band for polarimetric SAR interferometry applications. IEEE J. Sel. Top. Appl. Earth Obs. Remote Sens. 2013, 6, 1351-1367. [CrossRef]

19. Sexton, J.O.; Bax, T.; Siqueira, P.; Swenson, J.J.; Hensley, S. A comparison of lidar, radar, and field measurements of canopy height in pine and hardwood forests of southeastern North America. For. Ecol. Manag. 2009, 257, 1136-1147. [CrossRef]

20. Ross, M.; Ruiz, P.; Telesnicki, G.; Meeder, J. Estimating above-ground biomass and production in mangrove communities of Biscayne National Park, Florida (USA). Wetl. Ecol. Manag. 2001, 9, 27-37. [CrossRef]

21. Fromard, F.; Puig, H.; Mougin, E.; Marty, G.; Betoulle, J.L.; Cadamuro, L. Structure, above-ground biomass and dynamics of mangrove ecosystems: New data from French Guiana. Oecologia 1998, 115, 39-53. [CrossRef] [PubMed]

22. Feliciano, E.; Wdowinski, S.; Potts, M. Assessing Mangrove Above-Ground Biomass and Structure using Terrestrial Laser Scanning: A Case Study in the Everglades National Park. Wetlands 2014, 34. [CrossRef]

(C) 2017 by the authors. Licensee MDPI, Basel, Switzerland. This article is an open access article distributed under the terms and conditions of the Creative Commons Attribution (CC BY) license (http://creativecommons.org/licenses/by/4.0/). 